\title{
Research on the Information-based Teaching Ability Improving Path of Young University Teachers under the Background of "Internet+"
}

\author{
Yanjie Zhan \\ College of Business Administration, Tonghua Normal University, Tonghua, China \\ 82509380@qq.com
}

\begin{abstract}
Keywords: Young university teachers; Informatization; Teaching ability; Course design
\end{abstract}
\begin{abstract}
At present, internet has become an integral part in life, with the rapid development of informationalized level; the information-based teaching ability of young university teachers is highly valued by the education sectors which directly impacts the teaching level. Through researching on the current information-based teaching status and teaching ability of young university teachers, put forward the methods to improve the information-based teaching ability of young university teachers by the means of deepening the understanding, intensifying the training and creating the environment in thus to give references for the teaching quality and professional development of university teachers.
\end{abstract}

\section{Introduction}

"Internet+" refers to "internet+all traditional industries" which deeply integrates the internet and traditional industries through the information and communication technology and internet platform. In the era of "internet + ", the higher education in our country has entered the informationized education era comprehensively; the information technology deeply affects the traditional teaching methods. The information-based teaching takes the modern teaching ideas as the guidance, takes the information technology as support and applies the modern teaching method [1]. In the process of information-based teaching, it requires the informatization of the factors including idea, content, model, technology, evaluation and environment. The information-based teaching ability of the teachers determines the talents quality to some extent. Along with the increasingly enlarging education scale of universities, young teachers account for a larger proportion in all university teachers. According to the survey, the teachers below 40 years old account for $68 \%$, exceeding the two thirds of the normal college teachers [2]. Young teachers are the main force in the university development who must possess higher information-based teaching ability to adapt to the information-based society development. Therefore, how to improve the information-based teaching ability of young university teachers has become the major topic needing to be urgently solved for the researchers of higher education.

\section{The Current Information-based Teaching Status of Young University Teachers under the Background of "internet+"}

The development of teaching ability of young university teachers concerns about the top priority in the future development of universities. Nowadays, under the background of information-based teaching, it is needed to largely cultivate the information-based teaching ability of young university teachers and grasp the young teachers construction well [3]. However, young university teachers have lots of deficiencies in the information-based teaching which affect their work process and improvement of teaching ability.

Paying Less Attention to the Information-based Teaching. At present, young university teachers focus on scientific research instead of teaching. The main reason is that the universities pay attention to scientific research in evaluating the teachers, that is, pays more attention to the quantity and quality of scientific achievements in the evaluation of professional titles for young teachers, which results in faint teaching consciousness of young teachers. In order to get good professional evaluation and obtain more economic benefits, the young teachers put their main energies in scientific 
research instead of putting the time and energy in information-based teaching, therefore, they always take a wait-and-see attitude toward information-based teaching [4].

Lack of Actual Operating Ability. Many universities attach great importance to the information-based teaching equipment, take an overwhelming emphasis on the hardware equipment construction while neglect the input of software equipment, especially the information-based teaching training of young teachers[5]. Although some universities have organized some information-based teaching training of young teachers, there are no specific training, at the same time, the training form is single, and the training contents lack practicability, which causes the low information-based skills and low software operating ability of young university teachers to effectively apply the information technology[6].

Lack of Innovativeness in the Course Design. Under the background of "internet+", the information-based teaching ability of the teachers is the important part of their professional qualities which is the main capability in the teaching of the teachers. However, the young university teachers have certain deficiencies in the aspects such as course development, integration and design ability. The modern education idea is not embodied excellently, the students are not really taken as the main part in teaching, especially there is no effective guidance in cooperation learning and self-study, and the teaching design lacks systematization. The courses lack of innovativeness and the capability to integrate the information technology and professional courses reasonably and effectively. The media resources don't match with the courses and the demands of the students and there is no reasonable information-based learning environment.

\section{Compositions of the Information-based Teaching Ability of Young University Teachers}

The information-based teaching ability refers to the necessary individual psychological characteristic for the teachers to smoothly complete the design, development, application, management and evaluation of the learning process and learning resources under the information-based environment, and a new teaching ability forming in the constant information-based teaching practices[7]. The Several Suggestions on Comprehensively Improving the Higher Education Quality by the Ministry of Education makes specific requirements on improving the teaching level and ability of the teachers, wherein, especially for young teachers. The teaching idea, methods and contents of the university teachers has greatly changed under the background of "internet+". Currently, there is no unified idea on cognition of information-based teaching ability at domestic. New requirements are put forward for the information-based teaching ability of young university teachers in the information-based environment. Many scholars at domestic has researched on the cognition of information-based teaching ability while they have not formed a unified conclusion, different scholars have different ideas on the compositions of information-based teaching ability,( shown in table 1).

Based on the Guideline on Educational Technology Ability of National University Teachers (Trial Version) formulated and released by the Chinese Educational Technology Association in Higher Education in September of 2010, combined with the current information-based teaching status of universities and development need of young teachers under the background of "internet + ", the information-based teaching ability of young teachers are divided into 6 parts: the ability of integrating the modern information technology with the course, the ability of applying the modern information technology to design teaching, the ability of implementing the information-based teaching, the ability of designing and developing the modern information-based teaching resources, the ability of evaluating the modern information-based teaching effect, and the ability of supervising the modern information-based teaching[9]. 
Table 1 Different ideas on the compositions of information-based teaching ability from different scholars

\begin{tabular}{cl}
\hline Researchers & Compositions of information-based teaching ability \\
\hline Yan Wang & Basic information quality, the abilities of carrying out \\
& information-based teaching, resource management and solving, \\
& knowledge management and improving the scientific level, constant \\
& self-improvement through advanced educational thought[8]. \\
Hongyi Duan & Initially master the basic information and education technology, \\
& make applied teaching resources, carry out the course ability \\
& training, restructure the teaching process combining with the \\
& discipline features, make interaction among the teachers and the \\
& students based on the teaching platform, and improve the teaching \\
& level to cultivate famous teachers. \\
Wang Xing & The abilities of information collection, organization and integration, \\
& the abilities of knowledge updating, application and knowledge \\
& transferring, the abilities of course developing, integration and \\
design, the abilities of teaching organization, supervision and & evaluation, the abilities of research, innovation and practice. \\
The information-based teaching awareness, knowledge and \\
buqian Li
\end{tabular}

\section{The Paths to Improve the Information-based Teaching Ability of Young University Teachers}

The young university teachers have the master degree or above generally, though they are advantageous in professional knowledge, they still are deficient in basic quality and skills of teaching [10].

Enhance the Cognition of Information-based Teaching. To improve the information-based teaching ability of young university teachers, firstly, they should pay high attention to information-based teaching inwardly, recognize that they should focus on teaching, promote teaching based on scientific research, and constantly improve the teaching level. They should accept the educational thought inwardly and practice the information-based teaching in behavior [11]. As the managers of universities, they should change the thought of evaluating a teacher based on the scientific research and completion quantity of teaching tasks, establish the effective Information security mechanism, incentive mechanism and evaluation mechanism to take the mastery degree and application capability of information technology as the important factor to evaluate the professional level of the teachers and make the information-based teaching ability as the important basis of evaluating the teachers, thus to enhance the educational technology awareness of the teachers[12].

Intensify the Training of Information-based Teaching Ability. Many young university teachers are not with education specialty, though they have related skills training in teaching, they still need to be trained in the information-based teaching ability and information-based management ability[13]. Based on the current training status of young university teachers, for the training contents, the teachers should be strengthened in the aspects such as integration of information technology and professional courses, applying of network teaching platform and evaluation on information-based teaching methods. For the training methods, the method of combining the going-out and coming-in can be adopted, that is respectively, go to other universities to learn, exchange and visit; invite the professionals to explain the information-based teaching knowledge and skills thus to improve the information-based teaching ability of young university teachers[14].

Create Good Information-based Teaching Environment. The information-based teaching ability improvement of young university teachers relies on good hardware and software support. The good information technology environment support is necessary in the teaching practices which is the 
essential condition to guarantee the professional development of young teachers [15]. If the software and hardware environment cannot keep pace with the social development, it is inevitable to reduce the enthusiasm of the young university teachers on information-based teaching. Therefore, it is needed to build a good information-based teaching environment and pay attention to the management and maintenance of software and hardware environment [16].

\section{Conclusions}

Improving the information-based teaching ability of young university teachers is an important measurement to cultivate a high-quality teaching team under the "internet + " era. It is needed to rely on the joint efforts of the society, universities and teachers and adopt feasible measures to enhance the information-based teaching effects of young university teachers.

\section{Acknowledgements}

This work was financially supported by Education Scientific Project of Jilin Provincial Education Department (GH150435) and the Teaching Reform Research Project of Tonghua Normal University.

\section{References}

[1] X. Lu: Empirical Research on the Information-based Teaching Ability Cultivation of Young University Teachers-Taking One University in Sichuan as a Example (MS., Sichuan Normal University, China 2015), p.2.(In Chinese)

[2] F.Zhao and Y.P. Zhang: Science \& Technology Information, Vol. 13 (2013) No.16, p.173-179.(In Chinese)

[3] Information on http://baike.so.com/doc/7046525-7269431.html(In Chinese)

[4] J.J.Zhang and H.S.Wei: China New Telecommunications, Vol.17(2015) No.21, p.64.(In Chinese)

[5] J.L and J.J.Wang: Computer Knowledge and Skills, Vol.10 (2014) No.18, p.4197-4199.(In Chinese)

[6] Y. Zhang: Research on the Information-based Teaching Ability Development of New University Teachers (MS., Nanjing Normal University, China 2012), p.22.(In Chinese)

[7] Information on http://learning.sohu.com/20160830/n466776184.shtml(In Chinese)

[8] Y.Wang: Computer Knowledge and Skills, Vol. 10 (2014) No.8, p.1765-1767.(In Chinese)

[9] Y. Ge: Investigation and Research on the Information-based Teaching Ability of Middle School Teachers (MS., Central China Normal University, China 2010), p.32.(In Chinese)

[10] Information on http://news.k618.cn/edus/201607/t20160714_8121206.html(In Chinese)

[11] T.L.Li and L.Ma: Contemporary Teacher Education, Vol. 6 (2013) No.2, p.44-47.(In Chinese)

[12]Z.Zheng: Jiangsu Science \& Technology Information, Vol. 23 (2016) No.2, p.30-31.(In Chinese)

[13] S.X.Xie: Higher Education Forum, Vol. 29 (2015) No.11, p.99-102.(In Chinese)

[14] Information on http://www.jyb.cn/zgjyb/three/201608/t20160827_670259.html(In Chinese)

[15]X.L.Hu: Modern Remote Education, Vol. 29 (2012) No.6, p.67-72.(In Chinese)

[16] Information on http://club.topsage.com/thread-1383191-1-1.html(In Chinese) 